\title{
Editor's Corner
}

The Facts of Life - in Eight Sentences:

1. NALLD Journal publication expenses are paid for by our advertisers.

2. Without continued advertising business, we are out of business, or our membership rates skyrocket.

3. Your new advertising manager can, at best, only engage customers the first time they decide to try the NALLD Journal as an advertising outlet to a potential market.

4. If our advertisers do not receive clearly evident responses which are directly attributed to the NALLD ad, they will not renew their ad with us for the next issue.

5. Hence, it is really up to YOU, the readers and owners of this Journal, to keep it alive by showing businessmen that you request information on their products because you saw their ad in the NALLD Journal.

6. If businessmen read letters that state "I saw your ad in the NALLD Jourmal" they will continue to advertise with us.

7. Help us and help yourself.

8. Write those letters today.

Newsletter of FL Radio Programs: Several foreign language specialists, including Philip D. Smith of West Chester State College (Pennsylvania) and Robert Nelson of the University of Illinois, are putting together a newsletter containing items of interest to teachers who are using or would like to use radio programs to supplement language classwork. The Newsletter of the Language by Radio Interest Group will first appear in November and be mailed to anyone sending five self-addressed and stamped legal size envelopes to Alan Garfinkel, Purdue University, Department of Modern Languages, West Lafayette, Indiana 47907. The first issue will contain bibliography, a partial list of teachers interested in radio, and information on SW reception. Several sources are being solicited to find support for the newsletter and/or subsequent research funds. 


\section{Editor's Corner}

Videocassette Technology: Videocassette Technology in American Education by George N. Gordon and Irving A. Falk, Educational Technology Publications, Englewood Cliffs, New Jersey 07632, became available for immediate delivery on June 15. The 176-page book is $\$ 7.95$.

Language Lab Bibliography: A recent ERIC publication should be of great value to members of the language profession. A Selective Annotated Bibliography for the Language Laboratcry 1959-1971 compiled by Mary Ellen B. Keck and Wm. Flint Smith. This bibliography is available from the Materials Center, MLA/ACTFL, 62 Fifth Avenue, New York 10011.

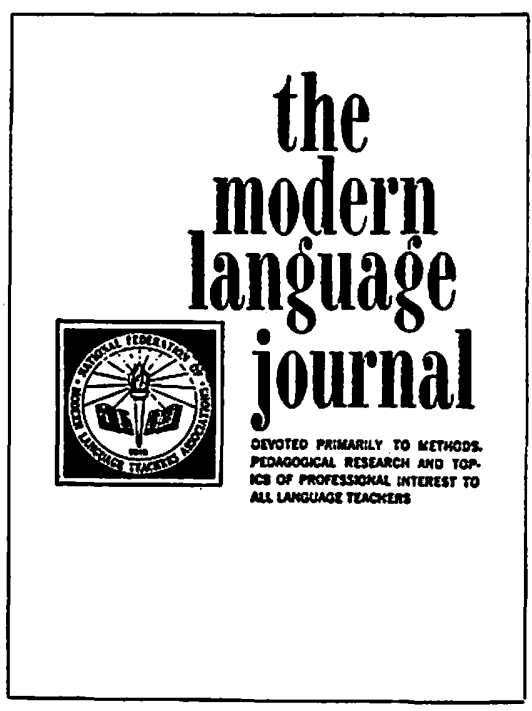

"The outstanding journal of modern language teaching in the United States" stimulating articles pedagogical research reviews of textbooks and teaching aids useful bibliographies timely announcements current advertisements

Edited by Charles L. King. The University of Colorado, Boulder, Colorado. Published by The National Federation of Modern Language Teachers Associations.

Six issues a year (September through April) ...\$6.00, (foreign subscriptions $\$ 7.50$ net in USA funds). Sample copy on request.

The Modern Language Journal Wallace G. Klein, Business Manager 13149 Cannes Drive St. Louis, Missouri 63141 